\title{
Commentary on interactions between neurotropic pathogens, neuroinflammatory pathways, and autophagic neural cell death
}

\author{
Michaela Cellina, Marcello Orsi \\ Radiology Department, ASST Fatebenefratelli Sacco, Milan 20121, Italy.
}

Correspondence to: Dr. Michaela Cellina, Radiology Department, ASST Fatebenefratelli Sacco, Piazza Principessa Clotilde, Milan 20121, Italy. E-mail: michaela.cellina@asst-fbf-sacco.it

How to cite this article: Cellina M, Orsi M. Commentary on interactions between neurotropic pathogens, neuroinflammatory pathways, and autophagic neural cell death. Neuroimmuno/ Neuroinflammation 2018;5:22.

http://dx.doi.org/10.20517/2347-8659.2018.15

Received: 30 Mar 2018 First Decision: 2 May 2018 Revised: 7 May 2018 Accepted: 7 May 2018 Published: 5 Jun 2018

Science Editor: Athanassios P. Kyritsis Copy Editor: Guang-Zhe Zhu Production Editor: Cai-Hong Wang

Autophagy is a fundamental regulatory cellular mechanism, which enables cells to survive after a checked clearance of damaged organelles and proteins and a recycle of necessary molecules like amino acids and fatty acids to maintain homeostasis ${ }^{[1]}$. There are a lot of factors able to influence autophagy in the states of health and disease. In the excellent review by Sahu et al ${ }^{[2]}$, the role of autophagy, its mechanisms, and its protective role against the attack of pathogens are well described. However, even more controversial aspects of autophagy are addressed: first some pathogens, such as herpes simplex viruses, coxsackievirus, listeria monocytogenes have developed strategies to circumvent autophagy-dependent activation of host immune response, then some bacteria have the ability to modify the gene transcriptional level of the autophagic process, both in terms of downgrading of autophagy-related genes, as in the case of Yersinia enterocolitica and Francisella tularensis ${ }^{[3]}$, and in terms of up regulation of autophagy-related genes: this mechanism favors a prolonged inflammation at the infection site and results in further injury to surrounding healthy tissues, causing brain matter degeneration.

The proposed hypothesis that prolonged infections of the central nervous system (CNS) by neurotropic pathogens, if associated with underlying conditions, might play a role in the pathogenesis of neurodegenerative diseases and the connections between autophagy dysregulation and neurodegeneration are subjects of great interest in literature.

Recent studies have demonstrated an intrinsic connection between selective autophagy impairment and neurodegenerative diseases, including Alzheimer's disease $(\mathrm{AD})^{[4-7]}$, Parkinson's disease $(\mathrm{PD})^{[8-10]}$, Huntington's 
disease $(\mathrm{HD})^{[11-14]}$, amyotrophic lateral sclerosis (ALS) $)^{[15-17]}$, and multiple sclerosis $(\mathrm{MS})^{[1,18-23]}$.

$\mathrm{AD}$ is a neurodegenerative chronic disorder characterized by a progressive cognitive decline; its main etiologic mechanisms are: deposition of extracellular amyloid- $\beta$ plaques, synaptic loss and evidence of intracellular neurofibrillary inclusions with hyper-phosphorylated tau protein.

Even if autophagy plays a complex role in $\mathrm{AD}$, which needs to be further characterized, the connection between this disease and autophagy dysregulation has been already demonstrated: a pathological accumulation of autophagosomes in neocortical of $\mathrm{AD}$ patients has been proved $^{[5]}$ and the mutations of presenilin-1, which are related to $\mathrm{AD}$ forms with early-onset, cause a block of the autophagy flux in fibroblasts in these patients ${ }^{[24,25]}$. On the other hand, other investigators suggest that early microglial accumulation in AD delays disease progression by promoting clearance of $A \beta$ before formation of senile plaques, therefore having a protective role ${ }^{[25]}$. The ability of microglia to clear A $\beta$ may decrease with age and progression of AD pathology ${ }^{[25]}$.

In PD one of the pathologic features is the presence of Lewy bodies, abnormal deposits of a protein called $\alpha$-synuclein: this fact is suggestive of defects in intracellular protein clearance mechanisms and autophagic process dysregulation ${ }^{[26]}$.

HD is caused by expansion of a CAG trinucleotide repeat in the first exon of the huntingtin gene that encodes the mutant huntingtin: this protein is highly expressed in neurons and participates in many cellular functions, including vesicle and organelle transport and autophagy ${ }^{[13,27]}$. Mutant huntingtin interferes with the correct autophagic function; therapeutic strategies that improve the clearance of this mutant protein by autophagy reduce neuronal toxicity ${ }^{[14]}$.

Recent genetic evidence has demonstrated that mutations in autophagy-regulatory genes can result in the occurrence of ALS ${ }^{[15-17]}$.

MS is a chronic immune-cell-mediated disease characterized by the presence of auto-reactive $\mathrm{T}$ cells target the myelin sheath in the $\mathrm{CNS}^{[18]}$, leading to inflammation, demyelination and neuronal function impairment. In patients affected by MS, several autophagy-related genes (e.g., ATG-16L2, ATG-9A, and ULK-1) are overexpressed ${ }^{[1]}$, therefore the hypothesis is that over-activation of autophagy may contribute to autoreactive $\mathrm{T}$ lymphocyte survival ${ }^{[18]}$.

Given the pivotal roles of the autophagy in these neurodegenerative diseases, the targeting of some key pathways of the inflammatory process provides new insights into the diagnosis and the modulation of this process represents a new therapeutic strategy for neuroprotection ${ }^{[1]}$.

The activated microglia plays a major role in chronic neuroinflammation, causing long-term cerebral damage by inducing autoimmune reaction, and is observed in various CNS diseases such as stroke, MS, ALS, AD and $\mathrm{PD}^{[28]}$. In vivo imaging of activated microglia can provide a non-invasive and reliable detection of early and localized neuroinflammation processes, thanks to the availability of several neuroimaging modalities ${ }^{[29]}$. Positron emission tomography (PET) is an imaging technique that can characterize measure and visualize the biological processes at the molecular levels in the body ${ }^{[28]}$.

In addition to the standard glucose metabolism [18F fluorodeoxyglucose (18F FDG) PET], a variety of targets for inflammation imaging have been recently discovered, and the corresponding PET tracers showed high levels of accuracy and are considered superior to FDG for imaging inflammation ${ }^{[30]}$. The most studied neuroinflammation related targets include translocator protein (TSPO), type 2 cannabinoid receptor (CB2R), and cyclooxygenase $(\mathrm{COX})^{[31]}$. 
TSPO is an $18 \mathrm{kDa}$ translocator protein located on the outer mitochondrial membrane. It is only minimally expressed in the healthy human brain, but highly expressed in macrophages, neutrophils, lymphocytes, astrocytes and microglia ${ }^{[32]}$. TSPO expression is highly up-regulated during the microglia activation process in several acute and degenerative disorders, including AD, PD, ALS, MS, and HD; therefore, TSPO is considered a promising target for PET imaging of neuroinflammation and has already undergone clinical application ${ }^{[30]}$. TSPO PET imaging, using various PET tracers binding to TPSO ${ }^{[33]}$, has been used for both improving the knowledge regarding the role of neuroinflammation in CNS diseases and to assess the efficacy of novel anti-inflammatory therapeutic strategies. In a rat brain $\mathrm{AD}$ model elevated TSPO levels were found in tau-rich hippocampus and entorhinal cortex region of the brain and there was a constant increase of tracer uptake in the brain region with the progression of $\mathrm{AD}^{[34]}$. In PD patients, microglia activation could be detected via TPSO PET at the early phase of the disease, and its activity is correlated with the development of dementia in $\mathrm{PD}^{[35]}$.

Cannabinoid receptors are a family of G-protein-coupled receptors composed at least by two subtypes: type 1 and 2. While type 1 is abundantly expressed in the brain, type 2, which is the inducible isoform, is detectable just in microglial cells, in human fetal astrocytes, and in human cerebral microvascular endothelial cells ${ }^{[36]}$. Several studies reported an up-regulation of $\mathrm{CB}_{2} \mathrm{R}$ on activated microglial cells in pathological conditions, including $\mathrm{MS}$, ALS, $\mathrm{PD}$, or $\mathrm{AD}^{[37]}$. The activation of $\mathrm{CB} 2 \mathrm{R}$ by $\mathrm{CB} 2$ agonists is found to be effective in reducing neurodegeneration in HD and ALS transgenic mouse model, thanks to the decrease of microglial activation, mediated by the release inhibition of neurotoxic factors and by the decrease of neuronal cell damage ${ }^{[38]}$. Therapeutic modulation of $\mathrm{CB} 2 \mathrm{R}$ could be a promising treatment for neuropathogenic disorders characterized by a neuroinflammatory component. Over the past years, several CB2R selective ligands have been developed and labeled with radioisotopes for PET, including pyrazole derivatives, indole derivatives, and quinoline derivatives ${ }^{[30]}$. The first in vivo PET of brain $\mathrm{CB}_{2} \mathrm{R}$ showed a significant increase in tracer uptake in all brain regions in mice with lipopolysaccharide induced neuroinflammation; in this study, tracer uptake could be blocked by a $\mathrm{CB} 2 \mathrm{R}$ selective ligand, thus indicating the specificity of the tracer accumulation ${ }^{[39]}$. New synthesized radiotracers are under investigations in the preclinical settings and offer promising opportunities for imaging $\mathrm{CB} 2 \mathrm{R}$ expression in the future ${ }^{[31]}$.

Cyclooxygenase (COX) is an enzyme producing important biological mediators mainly expressed in neuroinflammation in connection with neurodegenerative diseases. Three COX subtypes (COX-1, 2, and 3) have been identified. COX-2 is the inflammatory inducible enzyme form of this family and its expression in brain has been associated with neurodegenerative processes of several acute and chronic diseases ${ }^{[0]]}$.

COX-2 has been identified as a molecular target of interest for pharmacological design of selective ligands for both therapy and molecular imaging. Celecoxib is an important and widely used anti-inflammatory drug that inhibits selectively COX-2 to treat various inflammatory diseases. In order to image neuroinflammation, Celecoxib and other COX inhibitors were manipulated using imaging tracers ( $18 \mathrm{~F}$ and $11 \mathrm{C})$ : these attempts have not yet shown significant results due to the absence of specific bindings, sensitive enough to inflammatory foci ${ }^{[30]}$. On the other hand, a study of a rat skin model of inflammation showed significant uptake in COX-2 targeted micro PET/ computed tomography (CT) imaging of a mouse paw inflammation induced by carrageenan ${ }^{[41]}$.

Despite the fact that the administration of selective COX-2 inhibitors has been shown to attenuate brain inflammatory reactions, protecting neurons against neurodegeneration in $\mathrm{AD}$ patients ${ }^{[42]}$, the evidence of a direct role of COX-2 in neurodegenerative events is still controversial: recent data demonstrates that COX-1, classically viewed as the homeostatic isoform, is involved in brain injury induced by pro-inflammatory stimuli ${ }^{[43]}$.

Moreover, thanks to the recent discover of high specificity of cellular expression of COX-1 within microglia during acute neuroinflammatory process, the development of a selective COX-1 imaging probe has regained 
interest and it showed a better capacity to be depicted by PET in vivo ${ }^{[4]}$; in an animal model of AD, PET images clearly showed COX-1 expression in activated microglia during the formation of amyloid plaques ${ }^{[41]}$. PET imaging of COX-1, according to these preclinical studies, could be a promising approach for monitoring activated microglia in CNS diseases such as $\mathrm{AD}^{[31]}$.

Neuroinflammation plays a crucial role in the development of neurodegenerative disorders. The information extracted from molecular imaging of inflammation in the CNS could be fundamental for understanding the causes and effects of this entity, its relationship with various pathogens and other stimuli, and could be crucial in disease diagnosis, prognosis and in future therapies response monitoring. More specific biomarkers have to be identified and more sensitive imaging probes must be developed to improve visualization and quantification of the inflammatory processes and to better understand and characterize the interactions between neurotropic pathogens, neuroinflammatory pathways, and autophagic neural cell death and the CNS disorders progression.

\section{DECLARATIONS}

\section{Authors' contributions}

Worked on the first part of the article: Cellina $M$

Worked on the part of new perspectives: Orsi M

\section{Availability of data and materials}

Not applicable.

\section{Financial support and sponsorship}

None.

\section{Conflicts of interest}

All authors declared that there are no conflicts of interest.

\section{Ethical approval and consent to participate}

Not applicable.

\section{Consent for publication}

Not applicable.

\section{Copyright}

(c) The Author(s) 2018.

\section{REFERENCES}

1. Plaza-Zabala A, Sierra-Torre V, Sierra A. Autophagy and microglia: novel partners in neurodegeneration and aging. Int J Mol Sci 2017;18:1.

2. Sahu PS, Ter E. Interactions between neurotropic pathogens, neuroinflammatory pathways, and autophagic neural cell death. Neuroimmunol Neuroinflammation 2018;5:2.

3. Wileman T. Aggresomes and pericentriolar sites of virus assembly: cellular defense or viral design? Annu Rev Microbiol 2007;61:149-67.

4. Lau AA, Hemsley KM, Hopwood JJ, Sargeant TJ. Endo-lysosomal and autophagic dysfunction: a driving factor in Alzheimer's disease? J Neurochem 2017;140:703-17.

5. Nixon RA, Wegiel J, Kumar A, Yu WH, Peterhoff C, Cataldo A, Cuervo AM. Extensive involvement of autophagy in Alzheimer disease: an immuno-electron microscopy study. J Neuropathol Exp Neurol 2005;64:113-22.

6. Boland B, Kumar A, Lee S, Platt FM, Wegiel J, Yu WH, Nixon RA. Autophagy induction and autophagosome clearance in neurons: relationship to autophagic pathology in Alzheimer's disease. J Neurosci 2008;28:6926-37.

7. Yang DS, Stavrides P, Mohan PS, Kaushik S, Kumar A, Ohno M, Schmidt SD, Wesson D, Bandyopadhyay U, Jiang Y, Pawlik M, 
Peterhoff CM, Yang AJ, Wilson DA, St George-Hyslop P, Westaway D, Mathews PM, Levy E, Cuervo AM, Nixon RA. Reversal of autophagy dysfunction in the TgCRND8 mouse model of Alzheimer's disease ameliorates amyloid pathologies and memory deficits. Brain 2011;134:258-77.

8. Zhang J, Culp ML, Craver JG, Darley-Usmar V. Mitochondrial function and autophagy: integrating proteotoxic, redox, and metabolic stress in Parkinson's disease. J Neurochem 2018;144:691-709.

9. Chu Y, Dodiya H, Aebischer P, Olanow CW, Kordower JH. Alterations in lysosomal and proteasomal markers in Parkinson's disease: relationship to $\alpha$-synuclein inclusions. Neurobiol Dis 2009;35:385-98.

10. Dehay B, Bové J, Rodríguez-Muela N, Perier C, Recasens A, Boya P, Vila M. Pathogenic lysosomal depletion in Parkinson's disease. J Neurosci 2010;30:12535-44.

11. Ravikumar B, Vacher C, Berger Z, Davies JE, Luo S, Oroz LG, Scaravilli F, Easton DF, Duden R, O’Kane CJ, Rubinsztein DC. Inhibition of mTOR induces autophagy and reduces toxicity of polyglutamine expansions in fly and mouse models of Huntington disease. Nat Genet 2004;36:585-95.

12. Martin DDO, Ladha S, Ehrnhoefer DE, Hayden MR. Autophagy in Huntington disease and huntingtin in autophagy. Trends Neurosci 2015;38:26-35.

13. Caviston JP, Holzbaur ELF. Huntingtin as an essential integrator of intracellular vesicular trafficking. Trends Cell Biol 2009;19:147-55.

14. Ochaba J, Lukacsovich T, Csikos G, Zheng S, Margulis J, Salazar L, Mao K, Lau AL, Yeung SY, Humbert S, Saudou F, Klionsky D, Finkbeiner S, Zeitlin SO, Marsh JL, Housman DE, Thompson LM, Steffan JS. Potential function for the Huntingtin protein as a scaffold for selective autophagy. Proc Natl Acad Sci U S A 2014;111:16889-94.

15. Deng Z, Sheehan P, Chen S, Yue Z. Is amyotrophic lateral sclerosis/frontotemporal dementia an autophagy disease? Mol Neurodegener 2017;12:90.

16. Shahheydari H, Ragagnin A, Walker AK, Toth RP, Vidal M, Jagaraj CJ, Perri ER, Konopka A, Sultana JM, Atkin JD. Protein quality control and the amyotrophic lateral sclerosis/frontotemporal dementia continuum. Front Mol Neurosci 2017;10:119.

17. Weishaupt JH, Hyman T, Dikic I. Common molecular pathways in amyotrophic lateral sclerosis and frontotemporal dementia. Trends Mol Med 2016;22:769-83.

18. Alirezaei M, Fox HS, Flynn CT, Moore CS, Hebb AL, Frausto RF, Bhan V, Kiosses WB, Whitton JL, Robertson GS, Crocker SJ. Elevated ATG5 expression in autoimmune demyelination and multiple sclerosis. Autophagy 2009;5:152-8.

19. Igci M, Baysan M, Yigiter R, Ulasli M, Geyik S, Bayraktar R, Bozgeyik İ, Bozgeyik E, Bayram A, Cakmak EA. Gene expression profiles of autophagy-related genes in multiple sclerosis. Gene 2016;588:38-46.

20. Paunovic V, Petrovic IV, Milenkovic M, Janjetovic K, Pravica V, Dujmovic I, Milosevic E, Martinovic V, Mesaros S, Drulovic J, Trajkovic V. Autophagy-independent increase of ATG5 expression in T cells of multiple sclerosis patients. J Neuroimmunol 2018;319:100-5.

21. Keller CW, Lünemann JD. Noncanonical autophagy in dendritic cells triggers CNS autoimmunity. Autophagy 2018;14:560-1.

22. Moloudizargari M, Asghari MH, Ghobadi E, Fallah M, Rasouli S, Abdollahi M. Autophagy, its mechanisms and regulation: implications in neurodegenerative diseases. Ageing Res Rev 2017;40:64-74.

23. Patergnani S, Castellazzi M, Bonora M, Marchi S, Casetta I, Pugliatti M, Giorgi C, Granieri E, Pinton P. Autophagy and mitophagy elements are increased in body fluids of multiple sclerosis-affected individuals. J Neurol Neurosurg Psychiatr 2018;89:439-41.

24. Lee JH, Yu WH, Kumar A, Lee S, Mohan PS, Peterhoff CM, Wolfe DM, Martinez-Vicente M, Massey AC, Sovak G, Sovak G, Uchiyama Y, Westaway D, Cuervo AM, Nixon RA. Lysosomal proteolysis and autophagy require presenilin 1 and are disrupted by Alzheimer-related PS1 mutations. Cell 2010;141:1146-58.

25. Hickman SE, Allison EK, El Khoury J. Microglial dysfunction and defective beta-amyloid clearance pathways in aging Alzheimer's disease mice. J Neurosci 2008;28:8354-60.

26. Kalia LV, Lang AE. Parkinson's disease. Lancet 2015;386:896-912.

27. Streit WJ, Mrak RE, Griffin WS. Microglia and neuroinflammation: a pathological perspective. J Neuroinflammation 2004;1:14.

28. Jacobs AH, Tavitian B. Noninvasive molecular imaging of neuroinflammation. J Cereb Blood Flow Metab 2012;32:1393-415.

29. Mankoff DA. A definition of molecular imaging. J Nucl Med 2007;48:18-21.

30. Wu C, Li F, Niu G, Chen X. PET imaging of inflammation biomarkers. Theranostics 2013;3:448-66.

31. Tronel C, Largeau B, Santiago Ribeiro MJ, Guilloteau D, Dupont AC, Arlicot N. Molecular targets for PET imaging of activated microglia: the current situation and future expectations. Int J Mol Sci 2017;18:E802.

32. Ching AS, Kuhnast B, Damont A, Roeda D, Tavitian B, Dolle F. Current paradigm of the 18-kDa translocator protein (TSPO) as a molecular target for PET imaging in neuroinflammation and neurodegenerative diseases. Insights Imaging 2012;3:111-9.

33. Hatori A, Yui J, Yamasaki T, Xie L, Kumata K, Fujinaga M, Fujinaga M, Yoshida Y, Ogawa M, Nengaki N, Kawamura K, Fukumura T, Zhang MR. PET imaging of lung inflammation with [18F]FEDAC, a radioligand for translocator protein (18 kDa). PLoS One 2012; 7:e45065.

34. Maeda J, Zhang MR, Okauchi T, Ji B, Ono M, Hattori S, Kumata K, Iwata N, Saido TC, Trojanowski JQ, Lee VM, Staufenbiel M, Tomiyama T, Mori H, Fukumura T, Suhara T, Higuchi M. In vivo positron emission tomographic imaging of glial responses to amyloidbeta and tau pathologies in mouse models of Alzheimer's disease and related disorders. J Neurosci 2011;31:4720-30.

35. Edison P, Ahmed I, Fan Z, Hinz R, Gelosa G, Ray Chaudhuri K, Walker Z, Turkheimer FE, Brooks DJ. Microglia, amyloid, and glucose metabolism in Parkinson's disease with and without dementia. Neuropsychopharmacology 2013;38:938-49.

36. Cabral GA, Raborn ES, Griffin L, Dennis J, Marciano-Cabral F. CB2 receptors in the brain: role in central immune function. Br J Pharmacol 2008;153:240-51. 
37. Onaivi ES. Cannabinoid receptors in brain: pharmacogenetics, neuropharmacology, neurotoxicology, and potential therapeutic applications. Int Rev Neurobiol 2009;88:335-69.

38. Eljaschewitsch E, Witting A, Mawrin C, Lee T, Schmidt PM, Wolf S, Hoertnagl H, Raine CS, Schneider-Stock R, Nitsch R, Ullrich O. The endocannabinoid anandamide protects neurons during CNS inflammation by induction of MKP-1 in microglial cells. Neuron 2006;49:67-79.

39. Horti AG, Gao Y, Ravert HT, Finley P, Valentine H, Wong DF, Endres CJ, Savonenko AV, Dannals RF. Synthesis and biodistribution of [11C]A-836339, a new potential radioligand for PET imaging of cannabinoid type 2 receptors (CB2). Bioorg Med Chem 2010;18:5202-7.

40. Minghetti L. Cyclooxygenase-2 (COX-2) in inflammatory and degenerative brain diseases. J Neuropathol Exp Neurol 2004;63:901-10.

41. Uddin MJ, Crews BC, Ghebreselasie K, Huda I, Kingsley PJ, Ansari MS, Tantawy MN, Reese J, Marnett LJ. Fluorinated COX-2 inhibitors as agents in PET imaging of inflammation and cancer. Cancer Prev Res 2011;4:1536-45.

42. Giovannini MG, Scali C, Prosperi C, Bellucci A, Pepeu G, Casamenti F. Experimental brain inflammation and neurodegeneration as model of Alzheimer's disease: protective effects of selective COX-2 inhibitors. Int J Immunopathol Pharmacol 2003;16:31-40.

43. Aïd S, Bosetti F. Targeting cyclooxygenases-1 and -2 in neuroinflammation: therapeutic implications. Biochimie 2011;93:46-51.

44. Shukuri M, Mawatari A, Ohno M, Suzuki M, Doi H, Watanabe Y, Onoe H. Detection of cyclooxygenase-1 in activated microglia during amyloid plaque progression: PET studies in Alzheimer's disease model mice. J Nucl Med 2016;57:291-6. 